\title{
Investigation of Deformation-Based Damage Limits of RC Columns for Different Seismic Codes
}

DOI:10.36909/jer.13835

\author{
Saeid Foroughi $*^{1}$, Suleyman Bahadir Yuksel ${ }^{1 \mathrm{a}}$ \\ ${ }^{1}$ Department of Civil Engineering, Konya Technical University, Konya, Turkey
}

\begin{abstract}
The seismic performance of reinforced-concrete columns is related to the expected damage limits under seismic loads and how this damage relates to safety of the structure. In order to assess the performance of reinforced-concrete columns under seismic loads, performancebased deformation and damage limits are proposed by the seismic codes. Adequacy of the deformation and damage limit levels given in the codes such as Seismic Evaluation and Retrofit of Existing Buildings Standard, ASCE/SEI-41 (2017) and Turkish Building Earthquake Code (2018) were evaluated by carrying out parametric studies for RC columns. Reinforced-concrete circular columns are designed in parametric studies to present the effects of various parameters such as concrete compressive strength, axial load levels and spiral reinforcement ratio on performance-based damage limits. Performance limits corresponding to each performance levels obtained by different seismic guidelines were compared. When the results obtained from the analyzes are examined, it has been observed that there are significantly different results in the cross-section damage limits values of ASCE/SEI-41 (2017) and TBEC (2018) regulation, which can change the performance level of the building. TBEC (2018) gives approximately 50\% conservative limitations when they are compared with the ASCE/SEI-41 (2017) limitations. As a result, TBDY (2018) seems to offer safer and ductile solutions than ASCE ASCE/SEI-41 (2017).
\end{abstract}

Key words: Columns, Seismic codes, Performance level, Damage limits, Deformation,

\section{INTRODUCTION}

The philosophy behind the proper design for Reinforced-concrete (RC) frames is to provide them with sufficient ductility (Abdelwahed, 2020). Lateral force and moment-resisting structural systems, have to be designed adequately in strength and ductility. The behavior of $\mathrm{RC}$ members subjected to seismic loads is mainly based on the ultimate strength of concrete and its ductility (Foroughi \& Yuksel, 2020; Yuksel \& Foroughi, 2019; Subramanian \& Velayutham, 2014). As the main lateral force and moment-resisting elements, the ductile 
deformation capacity of RC columns is a key factor for achieving the better seismic performance of the structures (Cheng et al., 2017). One of the most important steps of performance-based assessment procedures of RC buildings relies on the comparison of deformations obtained from nonlinear structural analyses with deformation performance limits, or acceptance criteria in other words (Xinxian et al., 2016; Yakut \& Solmaz, 2012).

Normally, the preliminary design of civil engineering structures is typically based on the traditional force-based design procedures, which are used to judge the performance of structures (Abd-Elhamed \& Mahmoud, 2016). The seismic collapse assessment of structures in numerous post-earthquake investigations in addition to many experimental researches have mainly attributed the structural collapse of RC structures to losing the lateral loading capacity of their vertical load-carrying members (Al-Ogaidi et al., 2021).

The seismic performance of a structure is related to the level of damage that will occur under the influence of a particular earthquake and how this damage will affect the safety and use of the structure. Therefore, in determining the seismic performance, it is important to calculate the deformations rather than the internal forces that occur in the building elements under the influence of earthquakes. The purpose of the nonlinear calculation methods to be used to determine the structural performances under earthquake effect is to calculate the plastic deformation and plastic rotation demands related to the ductile behavior for a given earthquake (Foroughi et al., 2020a; Foroughi \& Yuksel, 2019). Understanding the nonlinear response and damage characteristics of RC buildings subjected to significant earthquakes is essential for the assessment of the seismic performance of existing buildings, as well as the safe and economic design of new buildings (Foroughi et al., 2020b; Uçar et al., 2015). Knowing the behavior of load-bearing elements and the parameters affecting this behavior in $\mathrm{RC}$ structure design is very important in terms of seismic performance, as it will primarily affect the elements and then the entire building system (Meral, 2018). Limit values, which constitute an important part of the proposed methods in many earthquake codes to determine the earthquake safety of buildings, are determined according to many design parameters. In order to determine earthquake safety, first of all, it is necessary to determine the section damage level of each carrier element (Ulutaş, 2019; Ulutaş et al., 2015). In the evaluation methods of existing buildings, regulations generally determine the performance of the building elements based on their plastic rotational capacities (Elci \& Göker, 2018). The structural elements are therefore modeled by means of plastic hinges determined according to the non-linear behavior of the structure and the element properties (Özmen et al., 2007). Seismic-induced damages in RC buildings were primarily associated with materials low 
strength and poor properties (Iş1k, 2021; Işık et al., 2021).

Recently proposed changes to modeling and acceptance criteria in seismic regulations for $\mathrm{RC}$ columns suggest that a comprehensive examination is required for improved limit state definitions and their corresponding values. Columns that can be classified as primary members of these structures dominate the seismic performance of RC frame buildings. In this study, deformation-based damage limits for RC members, which were mentioned in ASCE/SEI-41 (2017) and TBEC (2018), have been analytically studied to determine the earthquake performance of structural members. In addition, the ASCE/SEI-41 (2017) procedures to determine the idealized shear force-chord rotation backbone curve of $\mathrm{RC}$ circular columns are reviewed. Circular columns are generated in parametric studies to present the effects of various parameters such as concrete grade, axial load levels and spiral reinforcement ratios on performance-based displacement limits. Deformation values for RC columns were calculated at the performance levels defined in ASCE/SEI-41 (2017) and TBEC (2018). Column damages corresponding to the displacement demands were obtained and the damage limits were evaluated. Determining the unit deformation demands, the allowable concrete and reinforcing steel deformation limits were calculated according to different section damage limits in RC ductile structural system elements where plastic deformations occur. According to the critical values obtained from the moment-curvature relations of the RC columns modeled according to the lumped plastic behavior, yield rotation values and plastic rotation values for the plastic hinge regions of the columns were calculated for different performance levels.

\section{PERFORMANCE LEVELS FOR REINFORCED CONCRETE MEMBERS}

In order to assess the performance of RC columns under a given earthquake effect, deformation-based damage limits are proposed by seismic codes. ASCE/SEI-41 (2017) and TBEC (2018) seismic codes have defined three discrete damage limits and two performance ranges for flexure-dominant ductile members, as shown in Figure 1. In ASCE/SEI-41 (2017), the performance levels are Immediate Occupancy (IO), Life Safety (LS), and Collapse Prevention (CP). The damage limits are the Limited Damage (LD), Controlled Damage (CD) and Collapse Prevention (CP) structural performance levels as defined in TBEC (2018). 


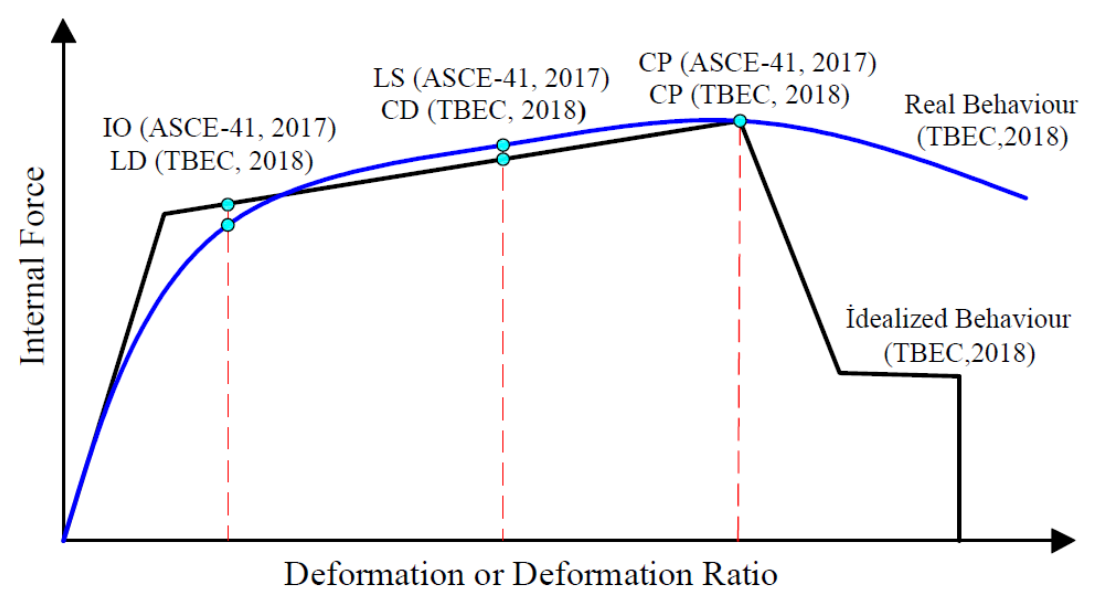

Figure 1. Performance limits for RC members

\section{Structural Performance Levels and Ranges According to ASCE/SEI-41 (2017)}

The main objective of this section is to assess the appropriateness of the ASCE/SEI-41 (2017) modeling parameters for the load-deformation relation behaviors of RC columns with various design details. After the chord yield rotation is determined, the deformation and strength parameters in Table 1 are used to establish the significant points (B, C, D, and E) in the idealized load-deformation relation backbone curve shown in Figure 2. The three parameters used to calculate modeling parameters and acceptance criteria of the RC circular columns; axial load levels, transverse reinforcement ratio and the ratio of shear demand at flexural yielding to shear capacity $\left(V_{y E} / V_{C o l O E}\right)$. The shear strength of RC columns in ASCE/SEI-41 (2017) is defined by Equation (1). In Equation (1), $V_{C o l}$ is the shear strength of concrete, $k_{n l}=1$ in regions where displacement ductility demand is less than or equal to 2, 0.7 in regions where displacement ductility is greater than or equal to $6 . \alpha_{\mathrm{Col}}=1$ for $s / d \leq 0.75, \alpha_{C o l}=0$ for $s / d \geq 1 . A_{v}$ is the area of shear reinforcement, $f_{y t L / E}$ expected yield strength of transverse reinforcement $\left(f_{y t E}=1.25 f_{y t}\right), f_{c L / E}^{\prime}$ expected concrete strength ( $\left.f_{C E}^{\prime}=1.5 f_{C}^{\prime}\right), d$ is the effective depth of a cross-section, $s$ is the spacing of transverse reinforcement, $A_{g}$ is the cross-section area of the column. $\lambda=1$ for normal-weight aggregate concrete. $N_{U G}$ axial force and $M_{U D} /\left(V_{U D} d\right)$ moment to shear times effective depth for the column.

$$
V_{\text {Col }}=k_{n l} V_{\text {Col0 }}=k_{n l}\left[\alpha_{C o l}\left(\frac{A_{v} f_{y t L / E} d}{s}\right)+\lambda\left(\frac{0.5 \sqrt{f_{c L / E}^{\prime}}}{M_{U D} /\left(V_{U D} d\right)} \sqrt{1+\frac{N_{U G}}{0.5 A_{g} \sqrt{f_{c L / E}^{\prime}}}}\right) 0.8 A_{g}\right] \text { (1) }
$$




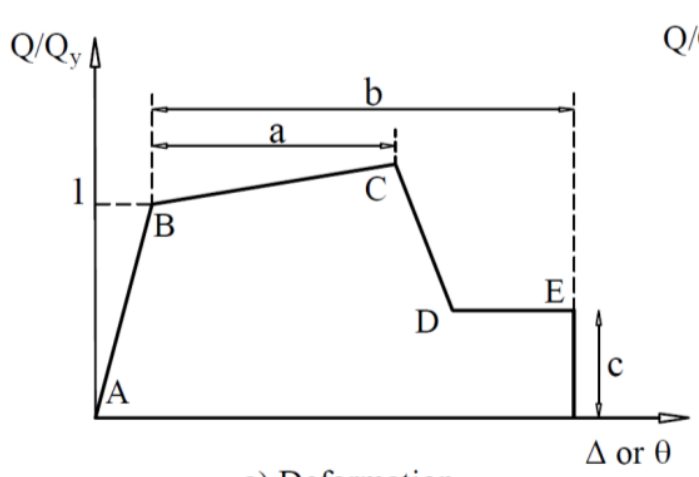

a) Deformation

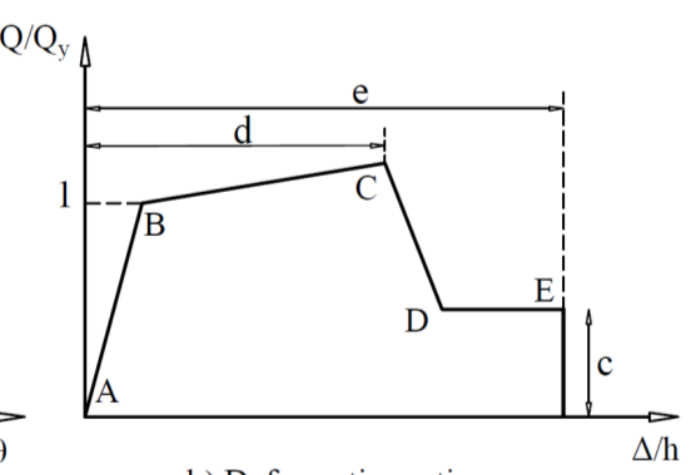

b) Deformation ratio

Figure 2. Generalized force-deformation relations for concrete elements or components

Table 1. Modeling parameters and numerical acceptance criteria for nonlinear procedures

\begin{tabular}{|c|c|c|c|}
\hline Modeling Parameters & \multicolumn{3}{|c|}{ Acceptance Criteria } \\
\hline \multicolumn{4}{|l|}{ Plastic rotation Angle (Radians) } \\
\hline \multirow{2}{*}{$\mathrm{a}$ and $\mathrm{b}$ (radians) Residual Strength Ratio, c } & \multicolumn{3}{|c|}{ Performance Level } \\
\hline & IO & LS & $\mathrm{CP}$ \\
\hline \multicolumn{4}{|c|}{ Columns not controlled by inadequate development or splicing along the clear height } \\
\hline$a=\left(0.06-0.06 \frac{N_{U D}}{A_{g} f_{C E}^{\prime}}+1.3 \rho_{t}-0.037 \frac{V_{y E}}{V_{\text {ColOE }}}\right) \geq 0$ & \multirow{3}{*}{$\begin{array}{l}0.15 a \\
\leq 0.005\end{array}$} & \multirow{3}{*}{$0.5 b$} & \multirow{3}{*}{$0.7 b$} \\
\hline for $\frac{N_{U D}}{A_{g} f_{C E}^{\prime}} \leq 0.5\left\{b=\frac{0.65}{5+\frac{N_{U D}}{0.8 A_{g} f_{C E}^{\prime}} \frac{1}{\rho_{t}} \frac{f_{C E}^{\prime}}{f_{y t E}}}-0.01 \geq a\right.$ & & & \\
\hline$c=0.24-0.4 \frac{N_{U D}}{A_{g} f_{C E}^{\prime}} \geq 0$ & & & \\
\hline
\end{tabular}

The Limit States for Structural Damages Proposed by TBEC (2018)

It has been updated as a result of developments in earthquake engineering and TBEC (2018) entered into force as of January 1, 2019. TBEC (2018) has introduced many new criteria, including deformation-based damage limits used in the description of element damage and performance targets to be considered during performance evaluation. It is seen that TBEC (2018) also focuses more on nonlinear analysis methods. Thus, with the renewed earthquake regulation, the way for more realistic earthquake loading and analysis results has been opened. In the nonlinear static procedure of TBEC (2018), in order to predict the performance level, the strain limits of concrete and steel are used as the main parameters. Three limit conditions have been defined for ductile elements on the cross-section (LD, CD, and $\mathrm{CP}$ ). In order to be used in the performance evaluation for the $\mathrm{LD}, \mathrm{CD}$ and $\mathrm{CP}$ performance level, the concrete and reinforcement steel calculated in accordance with the 
spreading plastic behavior model and the total deformation the limits allowed for their modification are defined in Table 2.

Table 2. Unit deformations according to different performance levels

\begin{tabular}{|c|c|c|}
\hline \multirow{2}{*}{ Deformation Limits } & \multicolumn{2}{|c|}{ Damage Limit } \\
\cline { 2 - 3 } & $\varepsilon_{\mathrm{c}}^{(\mathrm{LD})}=0.0025$ & Reinforcement \\
\hline Limited Damage (LD) & $\varepsilon_{c}^{(\mathrm{CD})}=0.75 \varepsilon_{c}^{(C P)}$ & $\varepsilon_{\mathrm{s}}^{(\mathrm{LD})}=0.0075$ \\
\hline Controlled Damage (CD) & $\begin{array}{l}\varepsilon_{s}^{(\mathrm{CD})} \\
=0.75 \varepsilon_{s}^{(C P)}\end{array}$ \\
\hline Collapse Prevention $(\mathrm{CP})$ & $\varepsilon_{c}^{(\mathrm{CP})}=0.0035+0.07 \sqrt{\omega_{w e}} \leq 0.018$ & $\varepsilon_{s}^{(\mathrm{CP})}=0.40 \varepsilon_{s u}$ \\
\hline
\end{tabular}

The mechanical reinforcement ratio of the effective confining reinforcement $\left(\omega_{w e}\right)$ is calculated from Equation (2). The confinement effectiveness coefficient $\left(\alpha_{s e}\right)$ of the circular cross-section elements and volumetric spiral reinforcement ratio $\left(\rho_{s h}\right)$ is given in Equation (3).

$$
\begin{gathered}
\omega_{w e}=\alpha_{s e} \rho_{s h, \min } \frac{f_{y w e}}{f_{c e}}, f_{c e}=1.3 f_{c k}, f_{y e}=1.2 f_{y k} \\
\alpha_{s e}=\left(1-\frac{s}{2 D}\right)^{n}, \quad \rho_{s h}=\frac{2 A_{o s}}{D s}
\end{gathered}
$$

In the Equations (2) to (3), $A_{o s}$ and $s$ is the area and spacing of the spiral reinforcement, $D$ is the distance between the spiral reinforcement axes. $f_{y w e}$ is the expected yield strength of spiral reinforcement and $f_{c e}$; expected compressive strength of concrete. $n=2$ for the circular stirrup and $n=1$ for spiral reinforcement will be taken. The limits for plastic rotations calculated according to the lumped plastic behavior model in new RC building elements including tall buildings, was calculated by the equations given in Table 3 . The length of the plastic zone was taken as half of the depth of the member as suggested by the code $\left(L_{p}=\right.$ $0.5 h)$. If the shear force ratio of the RC section is calculated as $V_{e} / b_{w} d f_{c t m}<0.65$, the upper limits of the deformation calculated according to different performance levels are valid. If the shear force ratio is greater than 1.30, the upper deformation limits calculated for different performance levels will be reduced by multiplying by 0.50 . 
Table 3. Plastic rotations according to different performance levels

\begin{tabular}{|c|c|}
\hline Deformation Limits & Plastic Rotations \\
\hline Limited Damage (LD) & $\theta_{p}^{(\mathrm{LD})}=0$ \\
\hline Controlled Damage (CD) & $\theta_{p}^{(\mathrm{CD})}=0.75 \theta_{p}^{(C P)}$ \\
\hline Collapse Prevention (CP) & $\theta_{p}^{(\mathrm{CP})}=\frac{2}{3}\left[\left(\emptyset_{u}-\emptyset_{y}\right) L_{p}\left(1-0.5 \frac{L_{p}}{L_{s}}\right)+4.5 \emptyset_{u} d_{b}\right]$ \\
\hline
\end{tabular}

$\emptyset_{\mathrm{u}}, \emptyset_{y}$ : Maximum and Yield curvature, $L_{s}$ : Shear span, $d_{b}$ : longitudinal reinforcement diameters

\section{MATERIAL and METHOD}

$\mathrm{RC}$ columns having circular cross-sections were designed considering the regulations of ACI318 (2014) and TBEC (2018). The column models having diameters of 565mm circular cross-sections were designed (Table 4). Different spiral reinforcement diameters; $Ф 8 \mathrm{~mm}$, $\Phi 10 \mathrm{~mm}$ and $\Phi 12 \mathrm{~mm}$ and the spiral reinforcement spacing; 50mm, 60mm, 70mm and 80mm were selected in order to investigate the effect of the spiral reinforcement on the crosssection behavior. In all the models the longitudinal reinforcement was $8 \Phi 20 \mathrm{~mm}$. For all circular RC column models, C30, C40 and C50 were chosen as concrete grade and B420C was selected as reinforcement for the reinforcement behavior model (Table 5). The combined effect of vertical and seismic loads $\left(N_{d m}\right)$, cross-section area of RC column shall satisfy the condition $A_{c} \geq N_{d \max } / 0.40 f_{c k}$ (TBEC, 2018). To investigate the effect of axial force on the cross-section behavior, the models were investigated under four different axial load levels.

Table 4. Designed column section details

\begin{tabular}{|c|c|c|c|c|}
\hline $\begin{array}{c}\text { Cross-Section of RC Circular Column } \\
\text { Models }\end{array}$ & Reinforcement & $\begin{array}{l}\text { Material } \\
(\mathrm{MPa})\end{array}$ & $\begin{array}{c}\text { Transverse } \\
\text { Reinforcement }\end{array}$ & $\begin{array}{l}N \\
/ N_{\max }\end{array}$ \\
\hline \multirow{12}{*}{ Sectio } & \multirow{12}{*}{$8 Ф 20 \mathrm{~mm}$} & \multirow{12}{*}{$\begin{array}{l}\text { C30 } \\
\text { C40 } \\
\text { C50 }\end{array}$} & $\Phi 8 / 50 \mathrm{~mm}$ & \multirow{12}{*}{$\begin{array}{l}0.10 \\
0.20 \\
0.30 \\
0.40\end{array}$} \\
\hline & & & $\Phi 8 / 60 \mathrm{~mm}$ & \\
\hline & & & $\Phi 8 / 70 \mathrm{~mm}$ & \\
\hline & & & $\Phi 8 / 80 \mathrm{~mm}$ & \\
\hline & & & $\Phi 10 / 50 \mathrm{~mm}$ & \\
\hline & & & $\Phi 10 / 60 \mathrm{~mm}$ & \\
\hline & & & $\Phi 10 / 70 \mathrm{~mm}$ & \\
\hline & & & $\Phi 10 / 80 \mathrm{~mm}$ & \\
\hline & & & $\Phi 12 / 50 \mathrm{~mm}$ & \\
\hline & & & $\Phi 12 / 60 \mathrm{~mm}$ & \\
\hline & & & $\Phi 12 / 70 \mathrm{~mm}$ & \\
\hline & & & $\Phi 12 / 80 \mathrm{~mm}$ & \\
\hline
\end{tabular}


Table 5. Material parameters for concrete and reinforcement (TBEC, 2018)

\begin{tabular}{|c|c|c|}
\hline Standard Strength & Parameters & Values \\
\hline \multirow{3}{*}{$\begin{array}{c}\text { Concrete: } \\
\text { C30-C50 }\end{array}$} & Strain at maximum stress of unconfined concrete $\left(\varepsilon_{c o}\right)$ & 0.002 \\
\cline { 2 - 3 } & Ultimate compression strain of concrete $\left(\varepsilon_{c u}\right)$ & 0.0035 \\
\cline { 2 - 3 } & Characteristic value of concrete compressive strength $\left(f_{c k}\right)$ & $30-50 \mathrm{MPa}$ \\
\hline \multirow{4}{*}{$\begin{array}{c}\text { Reinforcement: } \\
\text { B420C }\end{array}$} & Yield strain of reinforcement $\left(\varepsilon_{s y}\right)$ & 0.0021 \\
\cline { 2 - 3 } & Strain hardening value of reinforcing steel $\left(\varepsilon_{s p}\right)$ & 0.008 \\
\cline { 2 - 3 } & Strain in reinforcing steel at ultimate strength $\left(\varepsilon_{s u}\right)$ & 0.08 \\
\cline { 2 - 3 } & Characteristic yield strength of reinforcement $\left(f_{v k}\right)$ & $420 \mathrm{MPa}$ \\
\cline { 2 - 3 } & Ultimate strength of reinforcement $\left(f_{s u}\right)$ & $550 \mathrm{MPa}$ \\
\hline
\end{tabular}

Circular columns are popular for column design in structures because their strength characteristics under seismic loads are similar in any direction. Spiral reinforcement plays an important role in improving the strength and ductility of columns, especially when subjected to severe ground motion. According to these properties, circular cross-section column models were considered in this study. It is aimed to examine the necessary conditions for using the nonlinear calculation method and to examine the seismic performances of circular cross-section RC columns in detail depending on the nonlinear calculation method. According to the results obtained from the nonlinear behavior of RC columns according to different design parameters, deformation limits and plastic hinge properties were calculated and compared for different performance levels given in ASCE/SEI-41 (2017) and TBEC (2018) codes. For this purpose, 144 RC circular column models were designed for different concrete compressive strength, spiral reinforcement ratio and different axial load levels. In the analysis, the element damage limits in ASCE/SEI-41 (2017) and TBEC (2018) were examined by taking into account the different axial load levels, spiral reinforcement ratio and concrete compressive strength of the RC circular column cross-section. These codes define the performance levels of RC components by using different performance limits. In addition, the ASCE/SEI-41 (2017) procedures to determine the idealized shear force-chord rotation backbone curve of RC circular columns are reviewed. The nonlinear behavior of RC circular columns were theoretically calculated from the cantilever column model. Cantilever columns exposed to different axial load levels were taken into consideration in the moment-curvature and stress-strain analysis of the columns. Accordingly, damage limits calculated according to TBEC (2018) and ASCE/SEI-41 (2017) regulations are valid for circular cantilever columns. 


\section{RESEARCH FINDINGS and DISCUSSION}

In the analysis, the element damage limits in ASCE/SEI-41 (2017) and TBEC (2018) were examined by taking into account the different axial load levels, spiral reinforcement ratio and concrete compressive strength of the RC circular column cross-section. The deformation limits were calculated for the levels of $\mathrm{LD}, \mathrm{CD}$ and $\mathrm{CP}$ structural performance levels as defined in TBEC (2018). The deformation limits were calculated for the levels of IO, LS and CP structural performance levels in ASCE/SEI-41 (2017). Column damages corresponding to the displacement demands were obtained and the damage limits were evaluated. For different performance levels, plastic rotation values were calculated for the plastic hinge regions of the columns.

\section{Deformation Limits for Different Performance Levels According to TBEC (2018)}

One of the most important steps in performance evaluation according to the nonlinear method of deformation limits for different performance levels is the determination of LD, $\mathrm{CD}$ and $\mathrm{CP}$ damage levels in structural elements. The damage limits given for reinforcement steel are obtained by multiplying the unit deformation value corresponding to the ultimate strain of reinforcement steel by constant coefficients (Table 6).

Table 6. The calculated reinforcing steel deformation limit values

\begin{tabular}{|c|c|c|c|c|}
\hline \multirow{2}{*}{ Material } & \multirow{2}{*}{ Deformation Limit } & \multicolumn{3}{|c|}{ Performance Level } \\
\cline { 3 - 5 } & & $\varepsilon_{s}^{(C P)}$ & $\varepsilon_{s}^{(C D)}$ & $\varepsilon_{s}^{(L D)}$ \\
\hline B420C & $\varepsilon_{s}$ & 0.0320 & 0.0240 & 0.0075 \\
\hline
\end{tabular}

The damage limits for the confined concrete $\left(\varepsilon_{c}^{(C P)}, \varepsilon_{c}^{(C D)}\right)$ are calculated based on the $f_{y e}$, $f_{c e}, \rho_{s h}$ and the configuration of the spiral reinforcement. Plastic rotational damage limits $\left(\theta_{p}\right)$ for different performance levels; are the functions of $\emptyset_{y}, \emptyset_{u}, L_{P}, L_{S}$ and $d_{b}$. Therefore, parameters affecting $\emptyset_{y}$ and $\emptyset_{u}$ values such as $f_{c k}, N / N_{\max }$ and $\rho_{s h}$ also affect the $\theta_{p}$ values. The upper limit values of the deformation of the column sections corresponding to the cross-section damage levels were obtained and presented in Table 7. The plastic rotation values of the RC circular columns calculated for different parameters are given in Table 8. 
Table 7. The calculated $\varepsilon_{c}$ values for different design parameters

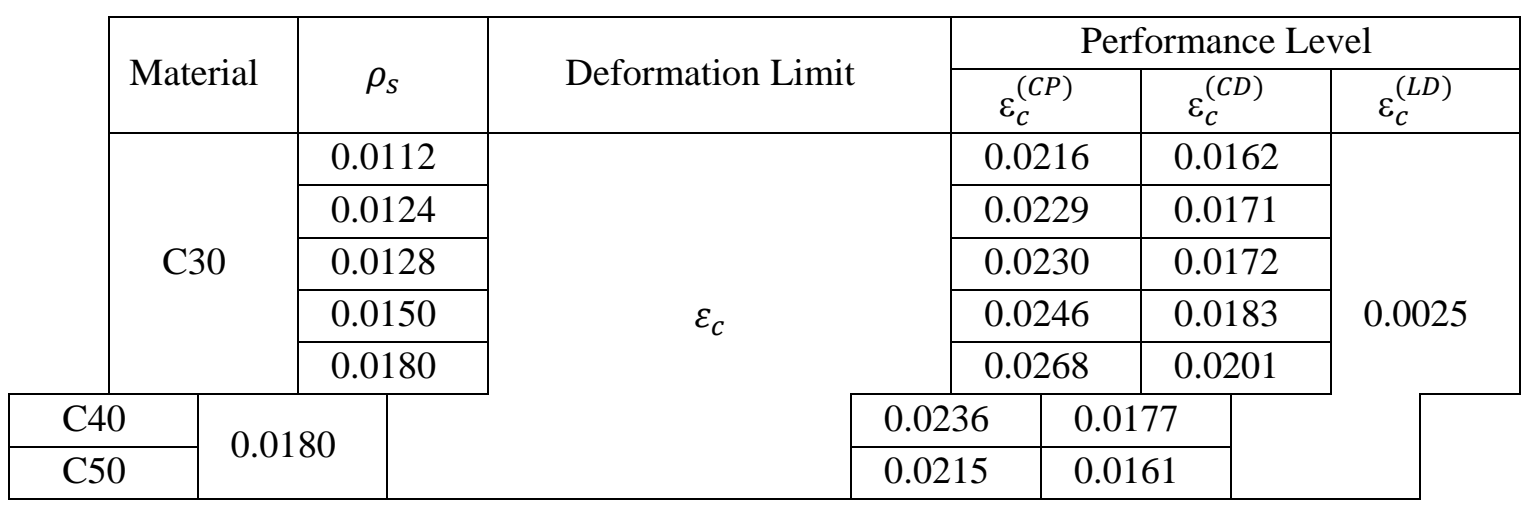

\section{Deformation Limits for Different Performance Levels According to ASCE/SEI 41 (2017)}

Load-deformation relationships were obtained for the RC column models by using provided guidelines in ASCE/SEI-41 (2017). For the nonlinear static procedure, the graphs describing the generalized force-deformation relationship for the RC circular columns are given in Figure 3. The three parameters that calculate modeling parameters and acceptance criteria for columns; are axial load ratio, spiral reinforcement ratio and the ratio of shear demand at flexural yielding to shear capacity $\left(V_{y E} / V_{\text {ColOE }}\right)$.
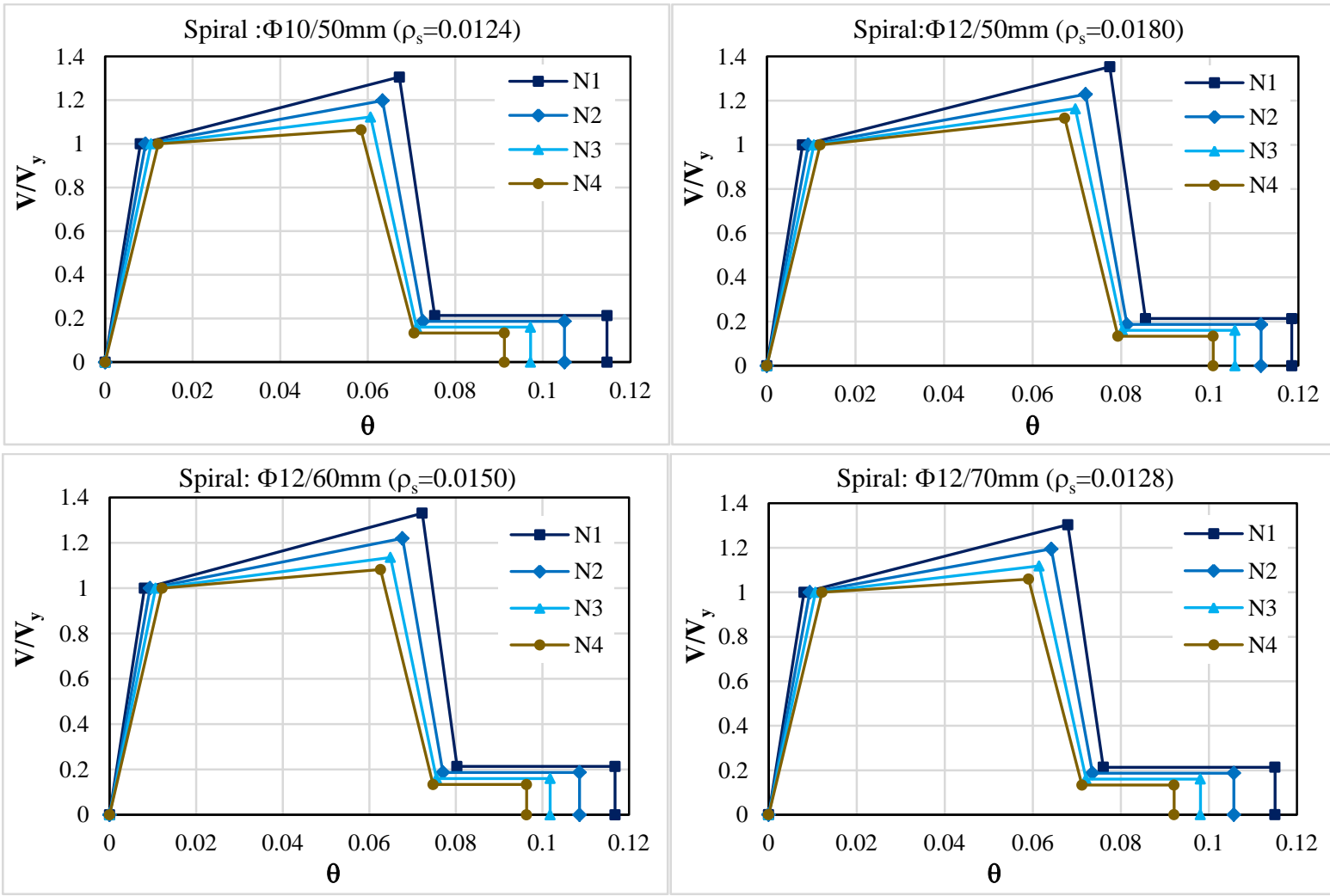

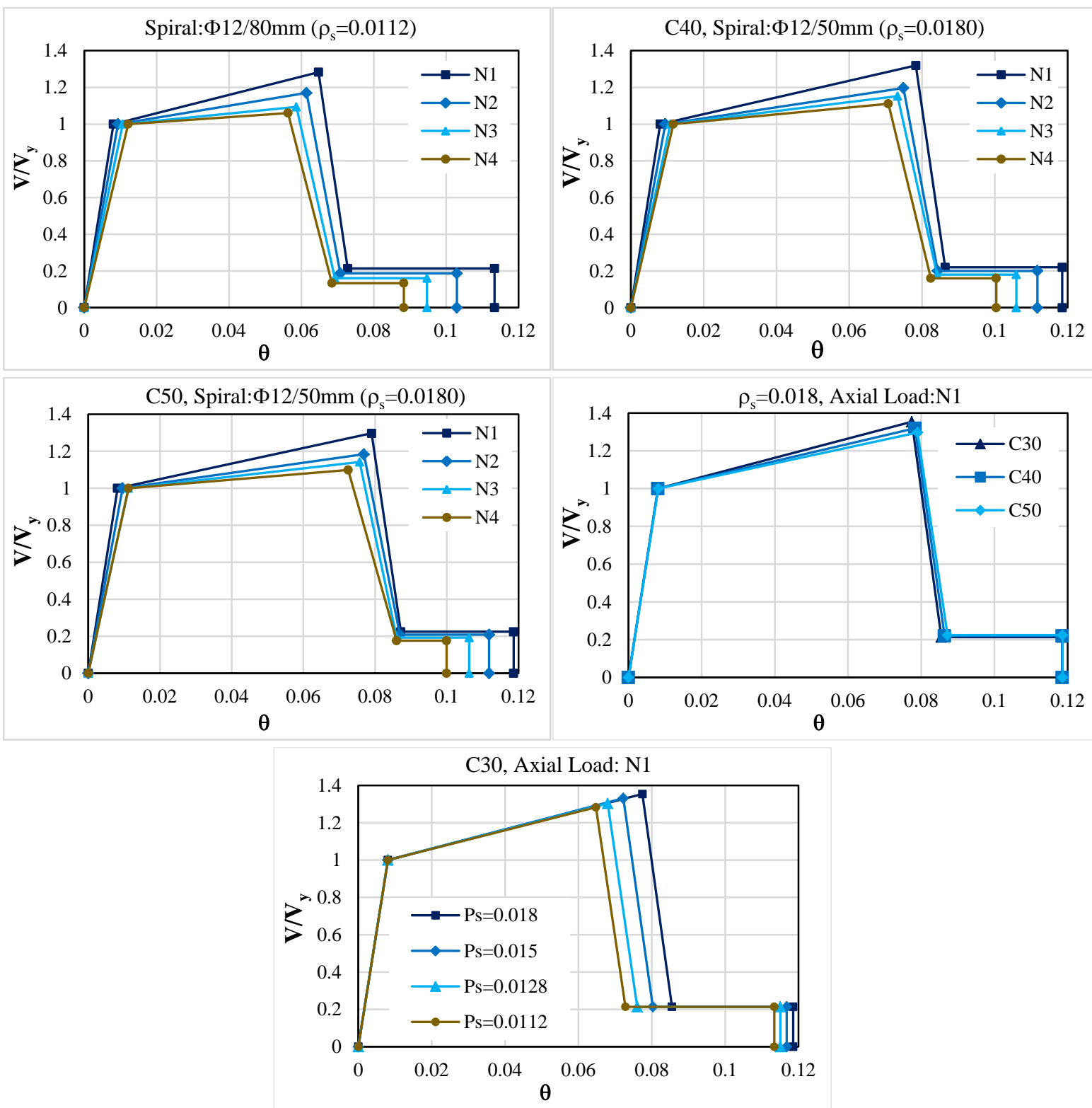

Figure 3. Generalized force-deformation relation according to ASCE/SEI-41 (2017)

According to ASCE/SEI-41 (2017); column model designed in $V / V_{y}$ value increases with the increase of $\rho_{s} . V / V_{y}$ value decreases with increasing $N / N_{\max }$ and decreases with increasing $f_{c k}$. The deformation ratio $(\theta)$ of the column models increase with the $\rho_{s}$ and $f_{c k}$. Deformation ratio decreases with increasing $N / N_{\max }$. LS and CP values increase with increasing $\rho_{s}$ and decrease with increasing $N / N_{\max }$. LS and CP values remain constant with increasing $f_{c k}$ in the circular column.

\section{Comparison of The Performance Levels Obtained}

Deformation limits for different performance levels according to ASCE/SEI-41 (2017) and TBEC (2018) are given in Figure 4. The results of the analyses for ASCE/SEI-41 (2017) are 
compared with the results of the TBEC (2018) in Tables (8). The differences between the performance level values calculated according to ASCE/SEI-41 (2017) and TBEC (2018) were obtained and the results are presented in Table 8 [D\% = (ASCE, 2017 - TBEC, 2018)/ ASCE, 2017)].
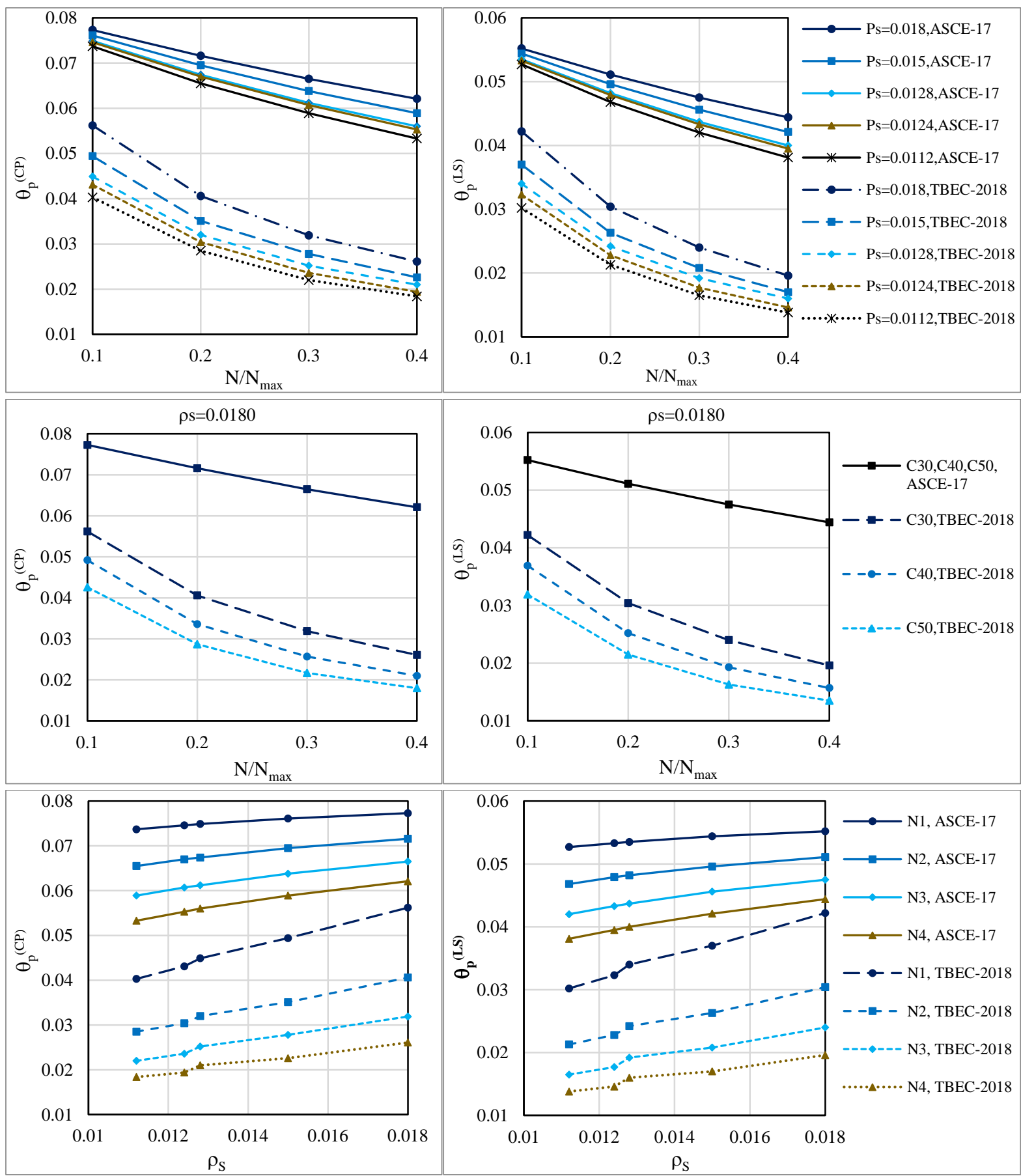

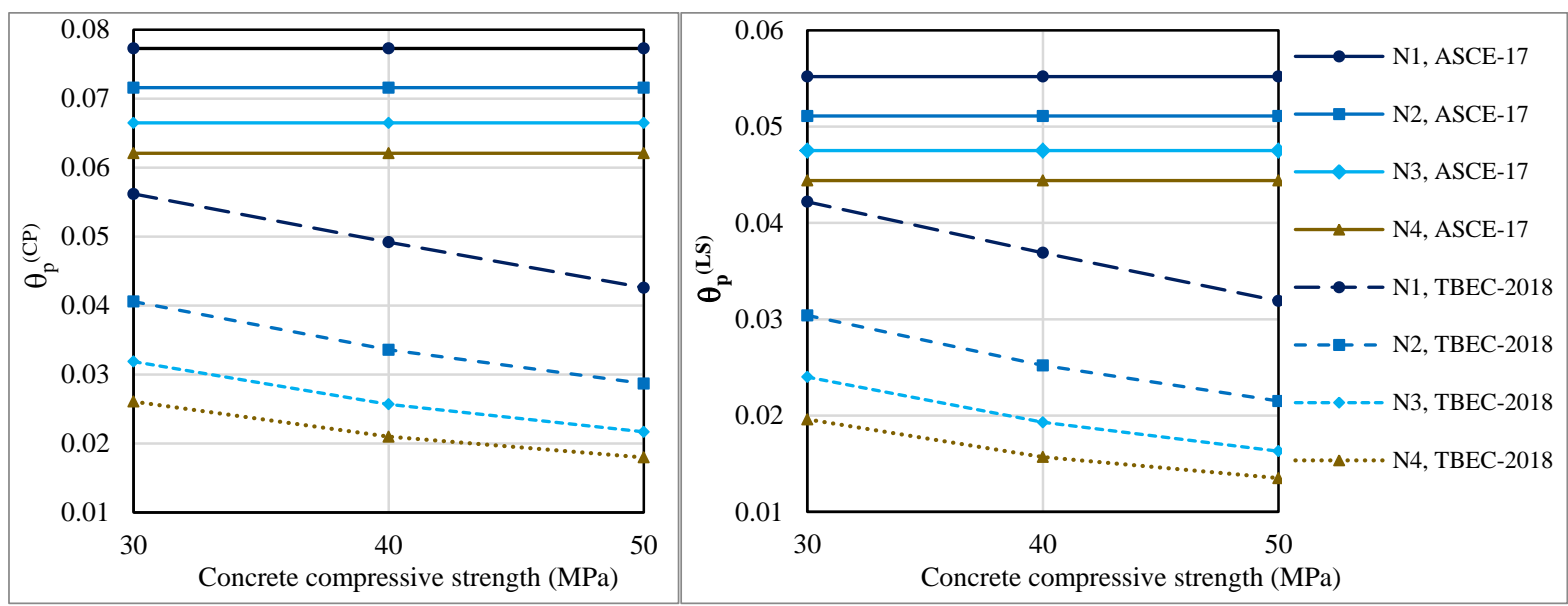

Figure 4. Comparison of deformation limits for different performance levels

Table 8. Comparison of performance levels calculated for the different design parameters

\begin{tabular}{|c|c|c|c|c|c|c|c|c|}
\hline \multirow{3}{*}{ Material } & \multirow{3}{*}{$\rho_{s}$} & \multirow{3}{*}{$N / N_{\max }$} & \multicolumn{6}{|c|}{ Performance Level } \\
\hline & & & \multicolumn{2}{|c|}{ ASCE/SEI-41. 2017} & \multicolumn{2}{|c|}{ TBEC. 2018} & \multicolumn{2}{|c|}{$\mathrm{D}(\%)$} \\
\hline & & & $\theta_{p}(\mathrm{LS})$ & $\theta_{p}(\mathrm{CP})$ & $\theta_{p}^{(C D)}$ & $\theta_{p}^{(C P)}$ & $\mathrm{LS}(\mathrm{CD})$ & $\mathrm{CP}$ \\
\hline \multirow{20}{*}{$\mathrm{C} 30$} & \multirow{4}{*}{0,0112} & 0.1 & 0.053 & 0.074 & 0.030 & 0.040 & 43 & 45 \\
\hline & & 0.2 & 0.047 & 0.066 & 0.021 & 0.029 & 54 & 56 \\
\hline & & 0.3 & 0.042 & 0.059 & 0.017 & 0.022 & 61 & 63 \\
\hline & & 0.4 & 0.038 & 0.053 & 0.014 & 0.018 & 64 & 65 \\
\hline & \multirow{4}{*}{0,0124} & 0.1 & 0.053 & 0.075 & 0.032 & 0.043 & 39 & 42 \\
\hline & & 0.2 & 0.048 & 0.067 & 0.023 & 0.030 & 52 & 55 \\
\hline & & 0.3 & 0.043 & 0.061 & 0.018 & 0.024 & 59 & 61 \\
\hline & & 0.4 & 0.040 & 0.055 & 0.015 & 0.019 & 63 & 65 \\
\hline & \multirow{4}{*}{0,0128} & 0.1 & 0.054 & 0.075 & 0.034 & 0.045 & 36 & 40 \\
\hline & & 0.2 & 0.048 & 0.067 & 0.024 & 0.032 & 50 & 53 \\
\hline & & 0.3 & 0.044 & 0.061 & 0.019 & 0.025 & 56 & 59 \\
\hline & & 0.4 & 0.040 & 0.056 & 0.016 & 0.021 & 60 & 63 \\
\hline & \multirow{4}{*}{0,015} & 0.1 & 0.054 & 0.076 & 0.037 & 0.049 & 32 & 35 \\
\hline & & 0.2 & 0.050 & 0.070 & 0.026 & 0.035 & 47 & 49 \\
\hline & & 0.3 & 0.046 & 0.064 & 0.021 & 0.028 & 54 & 56 \\
\hline & & 0.4 & 0.042 & 0.059 & 0.017 & 0.023 & 60 & 62 \\
\hline & \multirow{4}{*}{0,018} & 0.1 & 0.055 & 0.077 & 0.042 & 0.056 & 24 & 27 \\
\hline & & 0.2 & 0.051 & 0.072 & 0.030 & 0.041 & 41 & 43 \\
\hline & & 0.3 & 0.048 & 0.067 & 0.024 & 0.032 & 49 & 52 \\
\hline & & 0.4 & 0.044 & 0.062 & 0.020 & 0.026 & 56 & 58 \\
\hline \multirow{4}{*}{$\mathrm{C} 40$} & \multirow{8}{*}{0.018} & 0.1 & 0.055 & 0.077 & 0.037 & 0.049 & 33 & 36 \\
\hline & & 0.2 & 0.051 & 0.072 & 0.025 & 0.034 & 51 & 53 \\
\hline & & 0.3 & 0.048 & 0.067 & 0.019 & 0.026 & 59 & 61 \\
\hline & & 0.4 & 0.044 & 0.062 & 0.016 & 0.021 & 65 & 66 \\
\hline \multirow{4}{*}{$\mathrm{C} 50$} & & 0.1 & 0.055 & 0.077 & 0.032 & 0.043 & 42 & 45 \\
\hline & & 0.2 & 0.051 & 0.072 & 0.022 & 0.029 & 58 & 60 \\
\hline & & 0.3 & 0.048 & 0.067 & 0.016 & 0.022 & 66 & 67 \\
\hline & & 0.4 & 0.044 & 0.062 & 0.014 & 0.018 & 70 & 71 \\
\hline
\end{tabular}




\section{CONCLUSIONS}

Deformation-based damage limits calculated according to TBEC (2018) and ASCE/SEI-41 (2017) regulations are valid for circular cantilever columns. When the results obtained from the study are analyses, it has been observed that there are significantly different results in the cross-section damage limits values of ASCE/SEI-41 (2017) and TBEC (2018) regulation, which can change the performance level of the building. According to the evaluation of deformation limits the estimated damage limit for each performance level have average values of 0.09 (\%9) percent. It is seen that TBEC (2018) provides smaller values for all performance levels compared to ASCE/SEI-41 (2017). From the comparison of the damage limit values calculated for different performance levels, the ASCE regulation obtained a 51\% greater value for the LS and 54\% for the CP performance level according to the TBEC (2018) regulation. In both codes with the increase of spiral reinforcement ratio, plastic rotation values increase for LS (CD) and CP performance levels. With the increase of spiral reinforcement ratio, plastic rotation values increase for LS (CD) and CP performance levels. According to TBEC (2018) regulation, with increasing concrete compressive strength, plastic rotation values decrease for CD and CP performance levels (LS and CP performance levels calculated according to ASCE/SEI-41 (2017) remain constant). In both regulations in case of increasing axial load levels, plastic rotation values decrease for LS (CD) and CP performance levels. It is concluded that as the axial load levels increases, the damage limits become smaller, the amount of spiral reinforcement becomes more important at these load levels and the limitation stipulated by the regulation is highly effective. The difference between ASCE/SEI 41 (2017) and TBEC (2018) decreases with increasing spiral reinforcement ratio for $\mathrm{LS}(\mathrm{CD})$ and $\mathrm{CP}$ performance level. The difference for IO performance level is fixed. The differences between ASCE/SEI-41 (2017) and TBEC (2018) increase with increasing axial load levels and concrete compressive strength for different performance levels. TBEC (2018) gives approximately 50\% conservative limitations when they are compared with the ASCE/SEI-41 (2017) limitations. As a result, TBEC (2018) seems to offer safer and ductile solutions than ASCE ASCE/SEI-41 (2017). 


\section{REFERENCES}

Abdelwahed, B.S. 2020. A Review on RC Beam Column Joint: Role, Modeling and Recent Details. Journal of Engineering Research. 8(4): 63-79.

ACI 318. 2019. Building Code Requirements for Structural Concrete (ACI Standard), American Concrete Institute Committee, ISBN: 978-1-64195-056-5.

ASCE Standard, 41. 2017. Seismic Evaluation and Retrofit of Existing Buildings, (ASCE/SEI 41-17), Published by the American Society of Civil Engineers, Reston, Virginia, 20191-4382.

Abd-Elhamed, A. \& Mahmoud, S. 2016. Nonlinear static analysis of RC framed buildingsA case study on Cairo earthquake. Journal of Engineering Research. 4(4):1-23

Cheng, X.C., Bai, Z.Z. \& Au, F.T.K. 2017. Effect of Confinement on Flexural Ductility Design of Concrete Beams, Computers and Concrete, 20(2): 129-143.

Elci, H. \& Goker, K.A. 2018. Comparison of Earthquake Codes (TEC 2007 and TBEC 2018) In Terms of Seismic Performance of RC Columns, International Journal of Scientific and Technological Research. 4(6): 9-21.

Faiud Al-Ogaidi, Y.K., Wilson, J., Al-Mahaidi, R., Hashemi, J. \& Abdouka, K. 2021. Collapse Simulation of CFRP Retrofitted Column using Hybrid Testing Technique. Journal of Engineering Research. Vol 9 No ICRIE (2021): 1-15.

Foroughi, S., Jamal, R., \& Yüksel, B. 2020a. Effect of Confining Reinforcement and Axial Load In Determining Deformation Based Damage Limits. Journal of Engineering Sciences and Design. 8(4): 1042-1052.

Foroughi, S., Jamal, R. \& Yüksel, S.B. 2020b. Effect of Confining Reinforcement and Axial Load Level on Curvature Ductility and Effective Stiffness of RC Columns. El-Cezeri Journal of Science and Engineering. 7(3): 1309-1319.

Foroughi, S. \& Yuksel, S.B. 2020. Investigation of the Moment-Curvature Relationship for RC Square Columns, Turkish Journal of Engineering (TUJE), 4(1): 36-46.

Foroughi, S. \& Yuksel, S.B. 2019. Investigation of Deformation Based Damage Limits of RC Column. International Journal of Engineering Research and Development. 11(2): 584601.

Işık, E., Harirchian, E., Bilgin, H., \& Jadhav, K. 2021. The effect of material strength and discontinuity in RC structures according to different site-specific design spectra. Research on Engineering Structures \& Materials. 7(3): 413-430.

Işık, E. 2021. A comparative study on the structural performance of an RC building based on updated seismic design codes: case of Turkey. Challenge Journal of Structural Mechanics, 7(3): 123-134.

Meral, E. 2018. Effects of Structural Parameters on Curvature Ductility of RC Columns. Osmaniye Korkut Ata University Journal of Natural and Applied Sciences. 1(1): 28-43.

Özmen, H., İnel, M. \& Bilgin, H. 2007. Effect of Confined Concrete Behavior on RC Sections and Systems. Journal of the Faculty of Engineering and Architecture of Gazi University. 22(2): 375-383. 
Subramanian, K. \& Velayutham, M. 2014. Seismic performance of lateral load resisting systems, Structural Engineering and Mechanics. 51(3): 487-502.

TBEC. 2018. Specifications for Building Design Under Earthquake Effects", Turkish Building Earthquake Code, Ministry of Public Works and Housing, Turkey.

Ulutas, H. 2019. Comparison of TEC (2007) and TBEC (2018) Earthquake Codes in terms of Section Damage Limits. European Journal of Science and Technology. 17: 351-359.

Ulutaş, H., Tekeli, H. \& Demir, D. 2015. Confinement Effect on The Determining Seismic Damage Level. International Burdur Earthquake \& Environment Symposium (IBEES2015), 7-9 May 2015, Mehmet Akif Ersoy University, Burdur-Türkiye.

Ucar, T., Merter, O. \& Duzgun, M. 2015. Determination of lateral strength and ductility characteristics of existing mid-rise RC buildings in Turkey, Computers and Concrete, 16 (3): 467-485.

Xinxian, Z., Xiaolei, H., Jing, Ji., Yongle, Qi. \& Chao, H. 2016. Component-level Performance-based Seismic Assessment and Design Approach for Concrete Moment Frames, The Open Civil Engineering Journal (TOCIEJ), 10: 25-39.

Yüksel, S.B. \& Foroughi, S. 2019. Analytical Investigation of Confined and Unconfined Concrete Strength of RC Columns. Konya Journal of Engineering Sciences, 7(3): 611-629.

Yakut, A. \& Solmaz, T. 2012. Performance based Displacement Limits for RC Columns under Flexure, 15 Wcee, Lisboa. 